\title{
Price Responsiveness of Cigarette Demand in US: Retail Scanner Data (1994-2007)
}

\author{
Bishwa B. Adhikari, ${ }^{1}$ Chen Zhen, ${ }^{2}$ Jennifer W. Kahende, ${ }^{1}$ Joshua Goetz, ${ }^{2}$ and Brett Loomis ${ }^{2}$ \\ ${ }^{1}$ Office on Smoking and Health, National Center for Chronic Disease Prevention and Health Promotion, \\ Centers for Disease Control and Prevention, 4770 Buford Highway NE, Mailstop K-50, Atlanta, GA 30341, USA \\ ${ }^{2}$ RTI International, 3040 Cornwallis Road, P.O. Box 12194, Research Triangle Park, NC 27709, USA \\ Correspondence should be addressed to Bishwa B. Adhikari, bishwaa@gmail.com
}

Received 26 March 2012; Revised 12 June 2012; Accepted 14 June 2012

Academic Editor: Evžen Kočenda

Copyright (๑) 2012 Bishwa B. Adhikari et al. This is an open access article distributed under the Creative Commons Attribution License, which permits unrestricted use, distribution, and reproduction in any medium, provided the original work is properly cited.

This paper investigates the changes in cigarette demand in response to the changes in cigarette prices; smokeless tobacco prices; adoption of clean indoor air laws (CIALs). We used an error-correction econometric method to estimate the cigarette sales adjustment path in response to changes in prices and CIAL coverage in the United States by utilizing scanner data from supermarkets. Finding from this study indicates that smokeless tobaccos are not perfect substitutes for cigarettes, but increases in the price of cigarettes are associated with an increase in smokeless tobacco sales. The error-correction econometric method suggest that the demand for cigarettes and smokeless tobacco is related to each other; a price increase in either product leads to an increase in demand for the other product. However, the adjustment paths are quite different; an increase in cigarette prices lowers cigarette sales in relatively faster rate than decreases in smokeless tobacco prices or adoption of smoke-free laws. Changes in cigarette demand in response to changes in cigarette prices occur relatively quickly; but the full effects of smokeless tobacco price change and the adoption of $100 \%$ smoke-free laws on cigarette demand take a longer time.

\section{Introduction}

Cigarette smoking is associated with premature death, productivity losses, and a substantial burden to the health-care system in the United States $[1,2]$. Smoking causes several cancers, heart diseases, stroke, chronic respiratory diseases, and several other diseases $[2,3]$. In addition to the adverse health consequences and increased healthcare expenses, smoking is an expensive habit, and on average, approximately $\$ 1,000$ annually is spent on smoking per household with a smoker [4]. The economic burden of smoking continues to grow in the United States due to various reasons such as aging population, cohort of smokers suffering from smoking-related chronic diseases, more expensive healthcare services over time $[5,6]$, and stagnant smoking prevalence in recent years [3].

Smoking cessation is beneficial for all ages, but quitting at earlier ages is associated with greater health and economic benefits [7]. Tobacco control interventions such as increases in excise taxes, smoke-free air laws, individual and group counseling, telephone counseling, youth access laws, and health insurance coverage for cessation are effective public health interventions $[8,9]$. For example, increasing cigarette excise tax is an effective policy for lowering both smoking prevalence and per capita cigarette consumption. Prior studies on the effects of cigarette prices on consumption estimated the elasticity of demand to be approximately -0.3 to $-0.56[10-13]$. Similarly, ten percent increase in cigarette prices would likely decrease the smoking participation rate by $0.59 \%$ to $0.97 \%$ in the US [14].

Most studies that estimate the price responsiveness of cigarette demand use either person level survey data or aggregate data at the state or national level. This paper uses retail scanner data from supermarkets across the United States to estimate how quickly cigarette sales adjust to changes in cigarette price, changes in the price of smokeless tobacco, and coverage (adoption) of clean indoor air laws (CIALs). Retail scanner data are aggregate data from actual cigarette 
sales transactions. We used an error-correction econometric methodology [15] that allowed estimating the speed of cigarette sales adjusted in response to changes in cigarette price, changes in smokeless tobacco price, and the adoption of CIALs in the US.

\section{Data and Methods}

Cigarette and tobacco products sales data were obtained from ACNielsen Company. Data contained information on price, date of purchase, location of purchase, and product characteristics such as type of the product and brand name along with universal product codes (UPCs). Data were collected quarterly from a national sample of retail stores. The sampling area included all stores with annual total sales exceeding two million US. dollars. The sample included supermarkets and food stores with full-service pharmacies but excluded the convenience stores and mass merchandisers such as Wal-Mart. Scanner data from convenience stores were too expensive to collect, and sales data from mass merchandiser may not be representative. The data collection points were distributed in 50 US markets in metropolitan areas.

ACNielsen used a stratified random sampling technique to select points of sales (grocery stores) within the sampling area. Sales data from the selected stores were weighted to estimate the total sales of tobacco products for each stratum. We defined one unit of cigarette tobacco as approximately one pack (i.e., 20 cigarettes). For smokeless tobacco products, we defined a unit of smokeless tobacco as one pack of loose leaf, one tin of snuff, or one plug of chew regardless of type. We deflated prices to 2005 using the personal consumption expenditures price index (PCEPI) [16-18].

We obtained CIAL data from the American Nonsmokers' Rights foundation (http://www.no-smoke.org/). We limited our CIAL data to jurisdictions that had 100 percent smokefree laws in place and do not allow for separately ventilated smoking rooms and have no exemption for size of restaurants, restaurants with attached bars, free-standing bars, and nonhospitality workplaces. We used population data from the U.S. Census Bureau to determine the proportion of the population in each market covered by a 100 percent smokefree law, and then we summed population of all the jurisdictions within the market that are covered by 100 percent smoke-free laws. County-level annual per capita personal income data were obtained from the Bureau of Economic Analysis, US Department of Commerce. Per capita income, average price for cigarettes and smokeless tobacco, total dollar sales, and per capita dollar sales were deflated using the PCEPI. Descriptive statistics for the variables used in this analysis are presented in Table 1.

2.1. Econometric Models. We used a two-step modeling approach to analyze the effects of cigarette and smokeless tobacco prices and CIALs on cigarette sales in supermarkets. In the first step, we estimated the long-run relationship between per capita cigarette sales and the covariates. In the second step, we used an error-correction methodology [15] to estimate the adjustment path of cigarette sales which is a long-run dynamic relationship between cigarette demand and the explanatory variables.

The first-step model is

$$
\begin{aligned}
& C_{i t}= a_{i}+b_{1} \text { CPrice }_{i t}+b_{2} \text { SPrice }_{i t} \\
&+b_{3} \text { Income }_{i t}+b_{4} \text { CIAL }_{i t}+c_{1} \text { Quarter }_{i t} \\
& c_{2} \text { Year }_{i t}+c_{3} \text { Market }_{i t} \text { Trend }_{i t},
\end{aligned}
$$

where the subscripts $i$ and $t$ denote market and time period, respectively; $C$ is per capita cigarette sales; $C$ Price denotes average per pack cigarette price; SPrice is average price for one unit of smokeless tobacco (The types and qualities of raw tobacco used to manufacture cigarettes and smokeless tobacco are significantly different. There is high level of product differentiation. Smokeless tobacco products are taxed at a much lower rate than the cigarettes. Effect of price of raw tobacco on real prices of cigarettes is very small, and it is safe to assume that the CPrice and SPrice are independent to each other); Income indicates annual per capita personal income; CIAL denotes the percentage of the population covered by 100 percent smoke-free laws; Quarter represents vector of seasonal dummies; Year is a vector of year-specific dummies; Market $\times$ Trend represents market-specific time trends.

The seasonal dummy variable (quarter) captures seasonal variations in sales, and the variable Year is also included in the model to control for potential cross-sectional dependence arising from national demand shocks. The marketspecific trend terms are included to track the changes in the public sentiment toward smoking over time. We estimate (1) using five alternative specifications of CIAL, which were constructed as the percentage of the market population covered by CIALs in (1) workplaces or (2) restaurants or (3) bars or (4) any of the three places or (5) all of the three places.

Hendry and Richard [15] proposed a technique known as the error correction model (ECM), which is used when the dependent variable and covariates may be nonstationary. The ECM model can be specified as

$$
\begin{aligned}
\Delta C_{i t}= & \alpha_{i}+\sum_{k=0}^{K}\left(\beta_{1} \Delta \text { CPrice }_{i t-k}+\beta_{2} \Delta \text { SPrice }_{i t-k}\right. \\
& \left.+\beta_{3} \Delta \text { Income }_{i t-k}+\beta_{4} \Delta \text { CIAL }_{i t-k}\right) \\
& +\sum_{m=1}^{M} \theta_{m} \Delta C_{i t-m}+\lambda \text { Error Correction }_{t-1} \\
& +\gamma_{1} \text { Quarter }_{i t}+\gamma_{2} \text { Year }_{i t},
\end{aligned}
$$

where, $\Delta$ is the first difference operator (difference in two consecutive terms), and the term error correction is the regression residual obtained from the first-step regression (1). $\beta_{1}, \beta_{2}, \beta_{3}$, and $\beta_{4}$ are $K$-dimensional vectors of parameters; $\theta_{m}$ is an $M$-dimensional vector of parameters, where $K$ and $M$ are the optimal lag lengths for the first-differenced covariates determined empirically using the $F$ test. Because the dependent variable in (2) is in first-differenced form, the intercept $\alpha_{i}$ measures market-specific deterministic time trends. The coefficient $\lambda$ has to be negative for per capita 
cigarette sales to converge to its long-run equilibrium level. The magnitude of $\lambda$ is the speed of the adjustment of the system toward its long-run equilibrium. If $|\lambda|$ is close to 1 , the adjustment will be fast; if $|\lambda|$ is close to 0 , the adjustment process will be slow.

The parameters in (2) can be used to calculate the temporal adjustment path of per capita cigarette sales in response to a price shock or a change in the CIAL. The cumulative distributed lag adjustment process $S_{\text {cprice, } T}$ for per capita cigarette sales in response to a $\$ 1$ permanent increase in cigarette price is given by the following:

$$
\begin{gathered}
S_{c \text { price }, 0}=\beta_{10}, \\
S_{c \text { price }, 0}=S_{c \text { price }, 0}+\beta_{11}+\lambda\left(S_{c \text { price }, 0}-b_{1}\right)+\theta_{1} S_{c \text { price }, 0} \\
S_{c \text { price }, 2}=S_{c \text { price }, 1}+\beta_{12}+\lambda\left(S_{c \text { price }, 1}-b_{1}\right) \\
+\theta_{1}\left(S_{c \text { price }, 1}-S_{c \text { price }, 0}\right)+\theta_{2} S_{c \text { price }, 0} \\
\vdots \\
S_{\text {cprice } n}=S_{c \text { price }, n-1}+\beta_{1 n}+\lambda\left(S_{c \text { price }, n-1}-b_{1}\right) \\
+\sum_{m=1}^{M} \theta_{m}\left(S_{c \text { price }, n-m}-S_{c \text { price }, n-m-1}\right)
\end{gathered}
$$

where $\beta_{1 j}(j=1, \ldots, n)$ is the $j$ th element of the parameter vector $\beta_{2}, \beta_{2 j}=0$ for all $j>K$, and $n$ measures the number of periods past since the initial cigarette price shock.

Similarly, the cumulative distributed lag adjustment process $S_{\text {sprice }, T}$ for per capita cigarette sales in response to a $\$ 1$ permanent increase in smokeless tobacco price is given by the following:

$$
\begin{gathered}
S_{\text {sprice }, 0}=\beta_{20}, \\
S_{\text {sprice }, 1}=S_{\text {sprice }, 0}+\beta_{21}+\lambda\left(S_{\text {sprice }, 0}-b_{2}\right)+\theta_{1} S_{\text {sprice }, 0} \\
S_{\text {sprice }, 2}=S_{\text {sprice }, 1}+\beta_{22}+\lambda\left(S_{\text {sprice }, 1}-b_{2}\right) \\
+\theta_{1}\left(S_{\text {sprice }, 1}-S_{\text {sprice }, 0}\right) \\
\vdots \\
S_{\text {sprice } n=}=S_{\text {sprice }, n-1}+\beta_{2 n}+\lambda\left(S_{\text {sprice }, n-1}-b_{2}\right) \\
+\sum_{m=1}^{M} \theta_{m}\left(S_{\text {sprice }, n-m}-S_{\text {sprice }, n-m-1}\right)
\end{gathered}
$$

where $\beta_{2 j}(j=1, \ldots, n)$ is the $j$ th element of the parameter vector $\beta_{2}$, and $\beta_{2 j}=0$ for all $j>K$.
Finally, the cumulative distributed lag effect of a $1 \%$ permanent increase in the percentage of the population covered by CIALs is as follows:

$$
\begin{gathered}
S_{\text {cial }, 0}=0.01 \beta_{40}, \\
S_{\text {cial }, 1}=0.01\left\lfloor S_{\text {cial }, 0}+\beta_{41}+\lambda\left(S_{\text {cial }, 0}-b_{4}\right)+\theta_{1} S_{\text {cial }, 0}\right], \\
S_{\text {cial }, 2}=0.01\left[S_{\text {cial }, 1}+\beta_{42}+\lambda\left(S_{\text {cial }, 1}-b_{4}\right)\right. \\
\left.+\theta_{1}\left(S_{\text {cial }, 1}-S_{\text {cial }, 0}\right)+\theta_{2} S_{\text {cial }, 0}\right\rfloor \\
\vdots \\
S_{\text {cial }, n}=0.01\left[S_{\text {cial }, n-1}+\beta_{4 n}+\lambda\left(S_{\text {cial }, n-1}-b_{4}\right)\right. \\
\left.+\sum_{m=1}^{M} \theta_{m}\left(S_{\text {cial }, n-m}-S_{\text {cial }, n-m-1}\right)\right]
\end{gathered}
$$

where $\beta_{4 j}(j=1, \ldots, n)$ is the $j$ th element of the parameter vector $\beta_{4}$, and $\beta_{4 j}=0$ for all $j>K$.

2.2. Tests for Nonstationarity. The unit root test evaluates whether a time series variable is nonstationary and is important in time-series data like smoking policies where public sentiment toward smoking is evolving over time. If the dependent variable and some or all of the covariates in (1) are nonstationary, then statistical inference of parameter estimates in (1) using ordinary least squares (OLS) might be problematic, but simple correction may be applied to the standard OLS if the dependent variable is cointegrated with the covariates [19]. We tested for unit roots in cigarette price (CPrice), smokeless tobacco price (SPrice), income, and clean indoor air laws (CIALs).

The panel version of the augmented Dickey-Fuller (ADF) test proposed by Im et al. [20] estimates regression for each potentially nonstationary variable for each cross-section. The IPS panel unit root statistic is then a standardized tbar test statistic based on the ADF test statistics averaged across the cross-sections. The null hypothesis of the IPS test is that each series contains a unit root. Another test proposed by Pesaran, 2003, showed that panel unit root tests assuming cross-sectional independence may be biased toward concluding unit roots when there is substantial crosssectional dependence. He devised a cross-sectional augmented Dickey-Fuller (CADF) regression to remove the cross-sectional correlation. The IPS and CADF tests were applied to the per capita unit sales, prices, income, and clean indoor air variables. The test statistics for the first-differenced series indicated that the null of nonstationarity is rejected for most series and show the evidence that $C$, $C$ Price, SPrice, Income, and CIAL are integrated of degree one.

\section{Results and Discussion}

3.1. Parameters Estimates for Cigarette Sales. We estimated equation (1) using the panel fully modified ordinary least 
TABLE 1: Descriptive statistics for population, income, cigarettes, smokeless tobacco, and 100 percent smoke-free coverage, $1994-2007$.

\begin{tabular}{|c|c|c|c|c|}
\hline Variable & Mean & Std. dev. & Min & Max \\
\hline Market population & $4,315,888$ & $3,238,290$ & 966,087 & $20,000,000$ \\
\hline \multicolumn{5}{|l|}{ Income } \\
\hline Income (\$ per capita) & $28,729.82$ & $5,762.29$ & $17,709.02$ & $55,041.41$ \\
\hline Real income (\$ per capita) & $33,586.46$ & $5,295.50$ & $23,465.99$ & $56,560.95$ \\
\hline \multicolumn{5}{|l|}{ Cigarettes } \\
\hline Total cigarette sales $(\$)$ & $20,700,000$ & $10,300,000$ & $3,858,406$ & $63,200,000$ \\
\hline Cigarette sales (\$ per capita) & 5.64 & 2.59 & 0.98 & 15.80 \\
\hline Real cigarette sales (\$ per capita) & 6.71 & 3.19 & 1.04 & 19.98 \\
\hline Cigarette sales (pack) & $9,088,453$ & $5,342,387$ & 899,086 & $29,200,000$ \\
\hline Cigarette sold (pack per capita) & 2.58 & 1.65 & 0.25 & 9.82 \\
\hline Cigarette average price ( $\$$ per pack) & 2.59 & 0.88 & 1.22 & 5.36 \\
\hline Cigarette average price (real \$ per pack) & 3.00 & 0.88 & 1.58 & 5.64 \\
\hline \multicolumn{5}{|l|}{ Smokeless tobacco } \\
\hline Smokeless tobacco price (real \$) & 3.35 & 0.99 & 1.52 & 7.72 \\
\hline Smokeless units sold (per capita) & 0.15 & 0.19 & 0.00 & 1.17 \\
\hline Smokeless tobacco sales (real \$ per capita) & 0.40 & 0.38 & 0.00 & 1.97 \\
\hline Smokeless tobacco dollar sales & $1,120,970$ & $1,056,168$ & 174.12 & $5,894,168$ \\
\hline Smokeless tobacco unit sales & $4,96,258.90$ & $6,07,831.10$ & 45 & 3766479 \\
\hline Smokeless tobacco price & 2.86 & 0.93 & 1.15 & 6.72 \\
\hline Smokeless dollar sales (per capita) & 0.34 & 0.32 & 0 & 1.76 \\
\hline \multicolumn{5}{|l|}{ Clean indoor air laws (CIAL) coverage } \\
\hline Workplace coverage (percentage) & $7.7 \%$ & $21.9 \%$ & $0 \%$ & $100 \%$ \\
\hline Restaurant coverage (percentage) & $14.1 \%$ & $32.7 \%$ & $0 \%$ & $100 \%$ \\
\hline Freestanding bar coverage (percentage) & $8.8 \%$ & $26.7 \%$ & $0 \%$ & $100 \%$ \\
\hline Any CIAL coverage (percentage) & $14.9 \%$ & $32.7 \%$ & $0 \%$ & $100 \%$ \\
\hline All CIAL coverage (percentage) & $2.9 \%$ & $14 \%$ & $0 \%$ & $100 \%$ \\
\hline
\end{tabular}

squares (FMOLS) estimator for homogenous panels [19, 21, 22]. When unit roots are present in the stochastic variables, the OLS estimator is asymptotically biased [21]. The FMOLS estimator is a valid estimator for nonstationary panels. The estimator makes two nonparametric adjustments to the OLS estimator. It corrects for serial correlation in the regression residual of (1) and then it also corrects for the endogeneity of the stochastic covariates with the regression residual from (1). Endogeneity arises as a result of the dynamic feedback effects between the nonstationary-dependent variable and the nonstationary covariates over time.

The FMOLS and OLS estimates for (1) using the five different measures of population covered by CIALs are presented in Table 2. Most of the estimated coefficients have the expected signs and are statistically significant (few exceptions: indicated by the symbol $\Psi$ ). The coefficients on cigarette price and smokeless tobacco price (price elasticity and cross-price elasticity) indicate that cigarettes and smokeless tobacco prices have negative effects on each others sales. Similarly, coefficients on income suggest that growth in income has negative effect in volume of cigarette sales.

IPS and CADF test results suggest that the residuals are stationary in all five models (Table 3 ). This finding may be interpreted as evidence that there is a cointegration relationship between per capita cigarette sales and the stochastic covariates including cigarette and smokeless tobacco prices, per capita personal income, and the percentage of the population covered by CIALs. Because of this cointegration, the parameter estimates in Table 2 measure the long-run relationship between per capita sales and its covariates.

The estimated own-price elasticity of cigarette sales ranged from -0.75 to -0.73 (Table 2 ). The estimated crossprice elasticity of cigarette sales with respect to smokeless tobacco price is between 0.185 and 0.148 . It suggests that a $10 \%$ increase in smokeless tobacco price would increase cigarette sales by between $1.85 \%$ and $1.48 \%$. The effect of CIALs in bars is not statistically significant $(t$-value $=1.560)$. Of the four CIAL variables that have the expected negative effect on cigarette sales, three are highly statistically significant: percentage of population covered by workplace CIALs $(t$ value $=4.702)$, by restaurant CIALs $(t$-value $=3.667)$, and by any CIAL $(t$-value $=3.559)$. Although the estimated effect of the percentage of the population covered by all CIALs is negative, it is not statistically significant $(t$-value $=1.33)$. Workplace smoking bans are estimated to have the largest effect on cigarette sales. The coefficient estimate of -0.239 for workplace CIALs indicates that a 10 percent increase in the percentage of the population covered by workplace CIALs would reduce per capita supermarket cigarette sales by 2.39 packs in the long run. The mean estimated elasticity for workplace CIALs is -0.023 , meaning that a $10 \%$ increase in the workplace CIAL variable would reduce per capita 
TABLE 2: Panel fully modified ordinary least squares (FMLOS) estimates and the long-run elasticities.

(a)

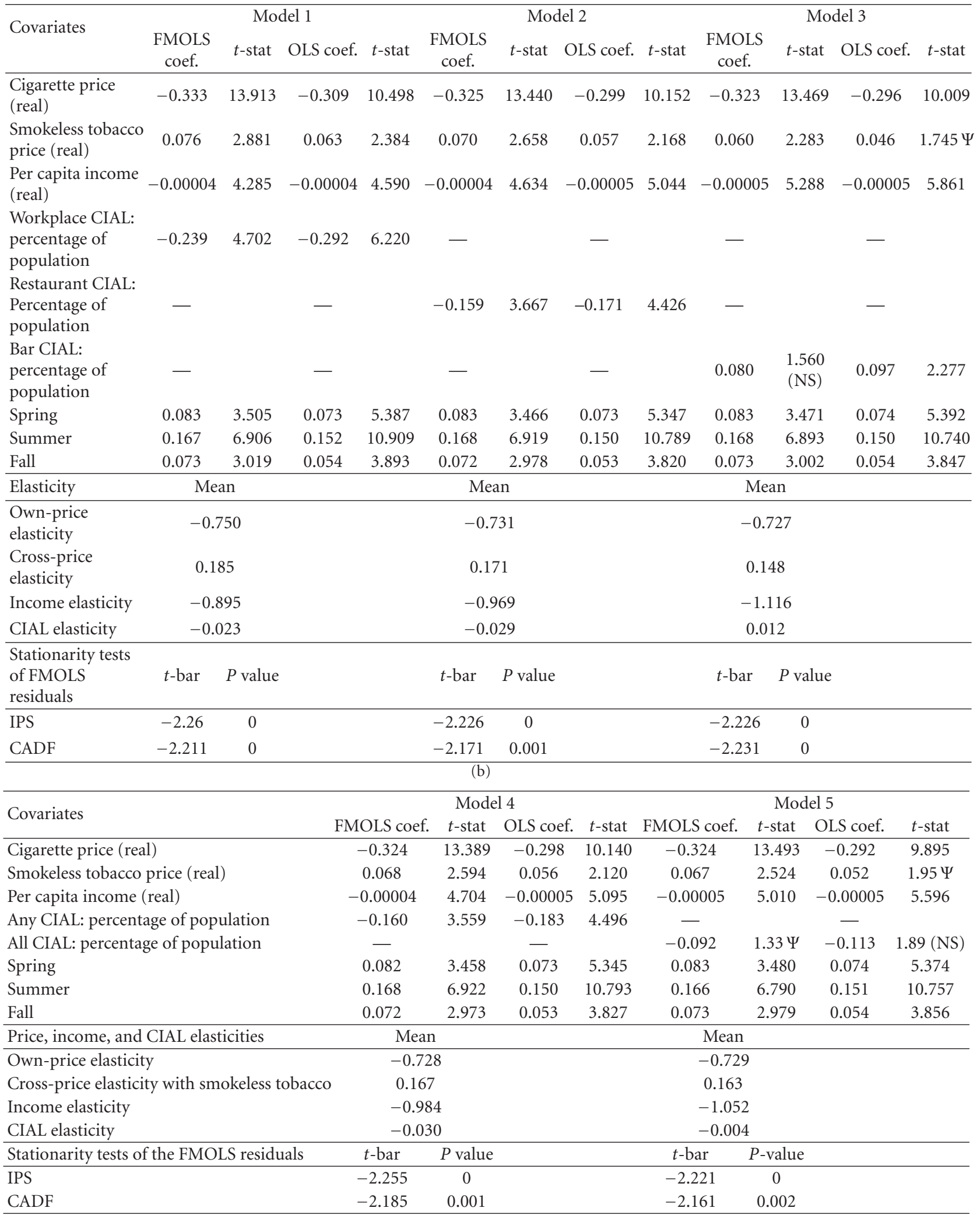

Note: all models include market-specific intercepts and time trends and year-specific intercepts. IPS denotes the Im et al. [20] test for nonstationarity; CADF denotes Pesaran's [40] cross-sectionally augmented Dickey-Fuller (CADF) test.

The symbol " $\Psi$ " next to the $t$-statistics indicates that the coefficient is not statistically significant at $5 \%$ sig. level. 
TABLE 3: Error-correction model estimates.

\begin{tabular}{|c|c|c|c|c|c|c|c|c|c|c|}
\hline \multirow{2}{*}{ Covariates } & \multicolumn{2}{|c|}{ Model 1} & \multicolumn{2}{|c|}{ Model 2} & \multicolumn{2}{|c|}{ Model 3} & \multicolumn{2}{|c|}{ Model 4} & \multicolumn{2}{|c|}{ Model 5} \\
\hline & Coef. & $P>|t|$ & Coef. & $P>|t|$ & Coef. & $P>|t|$ & Coef. & $P>|t|$ & Coef. & $P>|t|$ \\
\hline Cigarette price (real) & -0.379 & 0.000 & -0.376 & 0.000 & -0.374 & 0.000 & -0.376 & 0.000 & -0.375 & 0.000 \\
\hline $\begin{array}{l}\text { Smokeless tobacco price } \\
\text { (real) }\end{array}$ & 0.014 & 0.545 & 0.014 & 0.540 & 0.013 & 0.570 & 0.014 & 0.547 & 0.013 & 0.564 \\
\hline Per capita income (real) & -0.0000536 & 0.001 & -0.000055 & 0.000 & -0.0000578 & 0.000 & -0.0000551 & 0.000 & -0.0000566 & 0.000 \\
\hline $\begin{array}{l}\text { Workplace CIAL: } \\
\text { percentage of population }\end{array}$ & -0.062 & 0.209 & - & & - & & - & & - & \\
\hline $\begin{array}{l}\text { Restaurant CIAL: } \\
\text { percentage of population }\end{array}$ & - & & -0.02189 & 0.603 & - & & - & & - & \\
\hline $\begin{array}{l}\text { Bar CIAL: percentage of } \\
\text { population }\end{array}$ & - & & - & & 0.010 & 0.848 & - & & - & \\
\hline $\begin{array}{l}\text { Any CIAL: percentage of } \\
\text { population }\end{array}$ & - & & - & & - & & -0.031 & 0.481 & - & \\
\hline $\begin{array}{l}\text { All CIAL: percentage of } \\
\text { population }\end{array}$ & - & & - & & - & & - & & 0.011 & 0.874 \\
\hline Error correction (1st lag) & -0.213 & 0.000 & -0.21341 & 0.000 & -0.213 & 0.000 & -0.213 & 0.000 & -0.212 & 0.000 \\
\hline $\begin{array}{l}\text { Per capita cigarette units } \\
\text { (1st lag) }\end{array}$ & 0.095 & 0.000 & 0.095129 & 0.000 & 0.095 & 0.000 & 0.095 & 0.000 & 0.095 & 0.000 \\
\hline $\begin{array}{l}\text { Per capita cigarette units } \\
\text { (2nd lag) }\end{array}$ & -0.157 & 0.000 & -0.15729 & 0.000 & -0.158 & 0.000 & -0.157 & 0.000 & -0.158 & 0.000 \\
\hline Spring & 0.074 & 0.000 & 0.0741 & 0.000 & 0.074 & 0.000 & 0.074 & 0.000 & 0.074 & 0.000 \\
\hline Summer & 0.134 & 0.000 & 0.134347 & 0.000 & 0.134 & 0.000 & 0.134 & 0.000 & 0.134 & 0.000 \\
\hline Fall & 0.039 & 0.000 & 0.038818 & 0.000 & 0.039 & 0.000 & 0.039 & 0.000 & 0.039 & 0.000 \\
\hline
\end{tabular}

Note: The fully modified ordinary least squares (FMOLS) regression residual of (1) is used as the error correction term in (2).

CIAL: clean indoor air law.

cigarette sales in supermarkets by 0.23 percent. The CIAL variables, bounded between 0 and 1 , measure the percentage of the population covered by CIALs. Therefore, a one percent increase in a CIAL variable is usually less than a one percent increase in the percentage of the population covered by a CIAL. The OLS results indicate similar findings as those of the FMOLS, although the FMOLS estimated coefficient on the bar CIAL is positive but statistically not significant; the OLS counterpart estimate is positive and statistically significant (Table 2). This finding suggests that the FMOLS is preferred to the OLS estimator.

3.2. Error Correction Model Estimation. Parameter estimates for the error correction model (2) are presented in Table 3. The estimated coefficient on cigarette price (own-price) is statistically significant, but the coefficients on smokeless tobacco price and CIAL variables are not statistically significant. The results suggest that changes in smokeless tobacco price and percentage of the population covered by CIALs do not have an immediate effect on supermarket sales.

The $F$ test results indicated that including concurrent cigarette and smokeless tobacco prices, per capita personal income, CIAL variables, and lagged per capita cigarette sales up to two quarters in, (2) were sufficient in terms of model fit. Table 4 and Figure 1 (graph of model 1 only is presented for illustration purpose) present the quarterly cumulative distributed lag adjustment path for per capita cigarette sales, calculated using the FMOLS estimates in response to a permanent unit increase in cigarette price, smokeless tobacco price, and a one percent increase in the percentage of the population covered by CIALs. The adjustment path under each price or CIAL shock scenario is similar across the five models. For model 1, the short-run cumulative distributed lag response of cigarette sales to a one-time, $\$ 1$ increase in cigarette price oscillates between $97 \%$ and $122 \%$ of its longrun response. The full effect of a cigarette price change is realized about a year (four quarters) after the initial price shock. Cigarette sales adjust more slowly to changes in smokeless tobacco price and adoption of CIALs (Table 4 and Figure 1). It takes up to 15 quarters after the initial shock for sales to reach 97 percent of the long-run equilibrium level.

The estimated own-price elasticity $(-0.75$ to -0.73$)$ of cigarette sales is higher than the range of overall cigarette demand elasticity between -0.3 and -0.5 normally found in the literature. Supermarket cigarette sales account for only a small share of total cigarettes sold in the market. It may be possible that smokers who purchase cigarettes at supermarkets are more price sensitive than the smokers who buy cigarettes from other outlets where buyers may utilize discount coupons. Average supermarket cigarette sales have a lower price per pack than single-pack sales, and supermarket cigarette shoppers are more sensitive to price change. Stockpiling of cigarettes is not a money-saving strategy for smokers under the changes on smokeless tobacco price and CIAL, but it could be money-saving strategy in the case of cigarette price changes. 
TABLE 4: Distributed lag adjustment path of per capita cigarette sales.

(a)

\begin{tabular}{|c|c|c|c|c|c|c|c|c|c|c|c|c|}
\hline \multirow{3}{*}{$\begin{array}{l}\text { Quarters after the } \\
\text { shock }\end{array}$} & \multicolumn{6}{|c|}{ Model 1} & \multicolumn{6}{|c|}{ Model 2} \\
\hline & \multicolumn{2}{|c|}{ Own-price } & \multicolumn{2}{|c|}{ Cross-price } & \multicolumn{2}{|l|}{ CIAL } & \multicolumn{2}{|c|}{ Own-price } & \multicolumn{2}{|c|}{ Cross-price } & \multicolumn{2}{|l|}{ CIAL } \\
\hline & Change & $\%$ & Change & $\%$ & Change & $\%$ & Change & $\%$ & Change & $\%$ & Change & $\%$ \\
\hline 0 & -0.379 & 114 & 0.014 & 18 & -0.00062 & 26 & -0.376 & 116 & 0.014 & 20 & -0.00022 & 14 \\
\hline 1 & -0.405 & 122 & 0.028 & 37 & -0.00106 & 44 & -0.401 & 123 & 0.027 & 39 & -0.00053 & 34 \\
\hline 2 & -0.333 & 100 & 0.037 & 50 & -0.00129 & 54 & -0.328 & 101 & 0.035 & 50 & -0.00075 & 47 \\
\hline 3 & -0.322 & 97 & 0.044 & 59 & -0.00148 & 62 & -0.316 & 97 & 0.041 & 59 & -0.00090 & 57 \\
\hline 4 & -0.335 & 100 & 0.050 & 66 & -0.00165 & 69 & -0.328 & 101 & 0.047 & 67 & -0.00103 & 65 \\
\hline 5 & & & 0.055 & 73 & -0.00180 & 75 & & & 0.051 & 73 & -0.00114 & 72 \\
\hline 6 & & & 0.059 & 78 & -0.00191 & 80 & & & 0.055 & 78 & -0.00122 & 77 \\
\hline 7 & & & 0.062 & 82 & -0.00200 & 84 & & & 0.058 & 82 & -0.00129 & 81 \\
\hline 8 & & & 0.065 & 86 & -0.00208 & 87 & & & 0.060 & 86 & -0.00135 & 85 \\
\hline 9 & & & 0.067 & 88 & -0.00214 & 89 & & & 0.062 & 89 & -0.00139 & 88 \\
\hline 10 & & & 0.068 & 91 & -0.00219 & 91 & & & 0.064 & 91 & -0.00143 & 90 \\
\hline 11 & & & 0.070 & 92 & -0.00222 & 93 & & & 0.065 & 92 & -0.00146 & 92 \\
\hline 12 & & & 0.071 & 94 & -0.00226 & 94 & & & 0.066 & 94 & -0.00148 & 94 \\
\hline 13 & & & 0.072 & 95 & -0.00228 & 95 & & & 0.067 & 95 & -0.00150 & 95 \\
\hline 14 & & & 0.073 & 96 & -0.00230 & 96 & & & 0.067 & 96 & -0.00152 & 96 \\
\hline 15 & & & 0.073 & 97 & -0.00232 & 97 & & & 0.068 & 97 & -0.00153 & 97 \\
\hline
\end{tabular}

(b)

\begin{tabular}{|c|c|c|c|c|c|c|c|c|c|c|c|c|}
\hline \multirow{3}{*}{$\begin{array}{l}\text { Quarters after the } \\
\text { initial shock }\end{array}$} & \multicolumn{6}{|c|}{ Model 3} & \multicolumn{6}{|c|}{ Model 4} \\
\hline & \multicolumn{2}{|c|}{ Own-price } & \multicolumn{2}{|c|}{ Cross-price } & \multicolumn{2}{|c|}{$\mathrm{CIAL}^{ \pm}$} & \multicolumn{2}{|c|}{ Own-price } & \multicolumn{2}{|c|}{ Cross-price } & \multicolumn{2}{|c|}{ CIAL } \\
\hline & Change & $\%$ & Change & $\%$ & Change & $\%$ & Change & $\%$ & Change & $\%$ & Change & $\%$ \\
\hline 0 & -0.374 & 116 & 0.013 & 21 & - & - & -0.376 & 116 & 0.014 & 20 & -0.00031 & 19 \\
\hline 1 & -0.398 & 123 & 0.024 & 40 & - & - & -0.400 & 124 & 0.026 & 39 & -0.00061 & 38 \\
\hline 2 & -0.326 & 101 & 0.031 & 51 & - & - & -0.327 & 101 & 0.035 & 51 & -0.00081 & 50 \\
\hline 3 & -0.314 & 97 & 0.036 & 60 & - & - & -0.316 & 98 & 0.040 & 59 & -0.00095 & 59 \\
\hline 4 & -0.327 & 101 & 0.041 & 67 & - & - & -0.328 & 101 & 0.046 & 67 & -0.00107 & 67 \\
\hline 5 & & & 0.044 & 74 & - & - & & & 0.050 & 73 & -0.00117 & 73 \\
\hline 6 & & & 0.048 & 79 & - & - & & & 0.054 & 78 & -0.00126 & 78 \\
\hline 7 & & & 0.050 & 83 & - & - & & & 0.056 & 82 & -0.00132 & 82 \\
\hline 8 & & & 0.052 & 86 & - & - & & & 0.059 & 86 & -0.00138 & 86 \\
\hline 9 & & & 0.054 & 89 & - & - & & & 0.060 & 88 & -0.00142 & 88 \\
\hline 10 & & & 0.055 & 91 & - & - & & & 0.062 & 91 & -0.00145 & 91 \\
\hline 11 & & & 0.056 & 92 & - & - & & & 0.063 & 92 & -0.00148 & 92 \\
\hline 12 & & & 0.057 & 94 & - & - & & & 0.064 & 94 & -0.00151 & 94 \\
\hline 13 & & & 0.057 & 95 & - & - & & & 0.065 & 95 & -0.00152 & 95 \\
\hline 14 & & & 0.058 & 96 & - & - & & & 0.066 & 96 & -0.00154 & 96 \\
\hline 15 & & & 0.059 & 97 & - & - & & & 0.066 & 97 & -0.00155 & 97 \\
\hline
\end{tabular}

${ }^{ \pm}$Long-run effect of smoke-free laws on cigarette sales is not statistically significant in this model. Therefore, the adjustment path is not calculated. Percent change is the size of the response in a quarter as a percentage of the long-run response.

These results suggest that increasing cigarette prices by raising taxes will lower cigarette sales in supermarkets. A similar relationship exists between smokeless tobacco prices and smokeless tobacco sales volume. However, because cigarettes and smokeless tobacco are imperfect substitutes, price increase in either one will also have the effect of increasing sales in the other. The adoption of 100 percent smoke-free laws in workplace and restaurants should be promoted as another tool to lower cigarette sales.

Prior studies have examined the individual effects of tobacco control interventions including taxes and smoke-free air laws on cigarette sales. This study used scanner data and an error-correction method to estimate how quickly cigarettes sales adjust to own-price changes, smokeless tobacco 


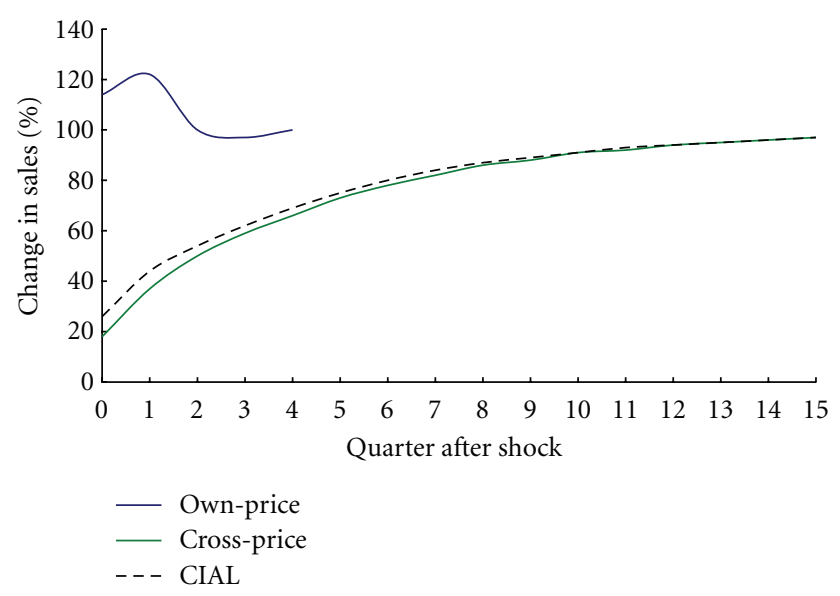

Figure 1: Distributed lag adjustment path of per capita cigarette sales Note: chart shows the adjustment path on per capita cigarette sales after the initial shock (model one in Table 4). Models two and four also exhibit similar paths of adjustment after the shock.

product prices, and the adoption of smoke-free air laws. We found that increasing cigarette prices (own-price) lowers cigarette demand (sales) much faster than the adjustment of cigarette sales due to the changes in the price of smokeless tobacco products (cross-price) or the adoption of smoke-free laws (CIALs).

The effects of tobacco control interventions such as increasing excise taxes on cigarettes and other tobacco products and implementation of smoke-free air laws are well documented. Studies show that increasing the price of cigarettes through excise taxes is the most effective intervention to reduce cigarette consumption [14, 23-30]. Hopkins et al. in 2001 reviewed the evidence on tobacco use interventions among youth and adults and concluded that increases in the price of tobacco products reduce the overall prevalence and the amount consumed [31]. Keller et al. [32] conducted an empirical analysis of local cigarette pricing and taxation and found that when state taxes are passed, the price of tobacco products increases. The price elasticity of demand, which measures the magnitude of change in consumption as a result of a change in the price of cigarettes, has been estimated at -0.4 , where a 10 percent price increase lowers consumption of cigarettes by 4 percent [33]. There is also sufficient evidence to show that implementing smoke-free air laws can reduce the onset of established smoking, encourage adult smokers to quit or reduce daily cigarette consumption, and reduce exposure to secondhand smoke among nonsmokers [34-38].

3.2.1. Limitations. This study has a few limitations. First, the sample is not nationally representative, as the sample was obtained from supermarkets and food stores with a fullservice pharmacy, but convenient stores, gas stations, and mass merchandisers such as Wal-Mart were excluded. Second, data on cigarette prices and cigarette sales for US markets were obtained from metropolitan areas only. Data are more likely to represent the urban smokers since the proportion of current smokers is generally higher in urban communities compared to rural areas [39]. Third, cigarette sales data were not observed but were projected using the sales data from the stores selected to estimate sales for each stratum. Fourth, CIALs data were limited to jurisdictions that have passed 100 percent smoke-free laws and we did not include the jurisdictions where partial smoking bans were in place. Also, although we had information on jurisdictions with smoke-free air laws, information on enforcement of such laws was not available. Despite these limitations, the strength of this analysis is in the use of retail scanner data and errorcorrection method, which has not been used before.

\section{Conclusions}

We estimated the impact of changes in cigarette price, smokeless tobacco price, and the adoption of CIALs on cigarette demand by using retail scanner data and applying an error-correction econometric technique. Our study found that per capita cigarette sales, cigarette prices, smokeless tobacco prices in supermarkets, and population coverage of 100 percent smoke-free laws are all nonstationary, and therefore, econometric methodologies such as FMLOS that account for the cointegration of time series variables are necessary for unbiased estimates. Higher per capita income and $100 \%$ smoke-free laws, are negatively associated with cigarette demand. The error-correction model suggests that effect of cigarette prices on cigarette sales is much faster than the adoption of $100 \%$ smoke-free laws or the change in the smokeless tobacco prices. The effects (the adjustment path) of smokeless tobacco price increases and coverage of smokefree laws on cigarette sales are similar but opposite.

The United States has a track record of effective tobacco control policies [20]. Historically, smoking prevalence in the United States has decreased substantially, but smoking still remains the leading preventable cause of premature death, resulting in an estimated 443,000 deaths annually [2]. The findings of this study indicate that increasing cigarettes prices is an effective policy tool for lowering cigarette demand. The findings also suggest that the price of smokeless tobacco products and the adoption of CIALs also affect the demand for cigarettes, although more slowly than a change in cigarette prices. This indicates that policies designed to increase cigarette prices, such as the imposition of excise taxes, may be more effective when combined with other policies such as changes in smokeless tobacco prices and the adoption of CIALs.

\section{Disclosure}

This study was conducted when one of the authors was working for Centers for Disease Control and Prevention, Office on Smoking and Health in Atlanta. The findings and conclusions in this paper are those of the authors and do not necessarily represent the official position of the Centers for Disease Control and Prevention/the Agency for Toxic Substances and Disease Registry. 


\section{Funding}

The study was funded by Office on Smoking and Health, Centers for Disease Control and Prevention, Atlanta, GA, USA.

\section{References}

[1] U.S. Department of Health and Human Services, Reducing Tobacco Use: A Report of the Surgeon General. U.S. Department of Health and Human Services, Centers for Disease Control and Prevention, National Center for Chronic Disease Prevention and Health Promotion, Office on Smoking and Health, Atlanta, GA, USA, 2000.

[2] Centers for Disease Control and Prevention, "Smoking-attributable mortality, years of potential life lost, and productivity losses-United States, 2000-2004," Morbidity and Mortality Weekly Report, vol. 57, pp. 1226-1228, 2008.

[3] Centers for Disease Control and Prevention, "Cigarette smoking among adults and trends in smoking cessation-United States 2008," Morbidity and Mortality Weekly Report, vol. 58, no. 44, pp. 1227-1232, 2009.

[4] S. H. Busch, M. Jofre-Bonet, T. A. Falba, and J. L. Sindelar, "Burning a hole in the budget: tobacco spending and its crowd-out of other goods," Applied Health Economics and Health Policy, vol. 3, no. 4, pp. 263-272, 2004.

[5] C. D. Baker, A. Caplan, K. Davis et al., "Shattuck lecture: health of the nation-coverage for all Americans," The New England Journal of Medicine, vol. 359, no. 8, pp. 777-780, 2008.

[6] M. I. Meltzer, "Health economics and prioritising health care," The Lancet, vol. 372, no. 9639, pp. 612-613, 2008.

[7] R. Doll, R. Peto, J. Boreham, and I. Sutherland, "Mortality from cancer in relation to smoking: 50 years observations on British doctors," British Journal of Cancer, vol. 92, no. 3, pp. 426-429, 2005.

[8] M. V. Maciosek, N. M. Edwards, A. B. Coffield et al., "Priorities among effective clinical preventive services. Methods," American Journal of Preventive Medicine, vol. 31, no. 1, pp. 90-96, 2006.

[9] Centers for Disease Control and Prevention, Best Practices for Comprehensive Tobacco Control Programs, US Department of Health and Human Services, CDC, Atlanta, Ga, USA, 2007.

[10] F. J. Chaloupka and H. Wechsler, "Price, tobacco control policies and smoking among young adults," Journal of Health Economics, vol. 16, no. 3, pp. 359-373, 1997.

[11] P. Zhang, C. Husten, and G. Giovino, "Effect of the tobacco price support program on cigarette consumption in the United States: an updated model," American Journal of Public Health, vol. 90, no. 5, pp. 746-750, 2000.

[12] E. Plamper, D.G. Klever, and K. W. Lauterbach, "Effects of tobacco tax increase on cigarette consumption and the impact on health policy," Bundesgesundheitsblatt Gesundheitsforschung Gesundheitsschutz, vol. 49, no. 7, pp. 660-664, 2006.

[13] M. C. Farrelly, C. T. Nimsch, A. Hyland, and M. Cummings, "The effects of higher cigarette prices on tar and nicotine consumption in a cohort of adult smokers," Health Economics, vol. 13, no. 1, pp. 49-58, 2004.

[14] M. C. Farrelly, T. F. Pechacek, K. Y. Thomas, and D. Nelson, "The impact of tobacco control programs on adult smoking," American Journal of Public Health, vol. 98, no. 2, pp. 304-309, 2008.

[15] D. F. Hendry and J. F. Richard, "The econometric analysis of economic time series," International Statistical Review, vol. 51, pp. 111-163, 1983.
[16] T. Clark, "A comparison of the CPI and PCE price index," Economic Review Q, vol. 3, pp. 15-29, 1999.

[17] D. Fixler and T. Jaditz, "An Examination of the Difference between the CPI and the PCE Deflator on the Formulation of the Differences between the CPI and PCE Deflator," Working paper 361, Washington, DC, USA, Bureau of Labor Statistics, 2002.

[18] J. Hausman, "Sources of bias and solutions to bias in the consumer price index," Journal of Economic Perspectives, vol. 17, no. 1, pp. 23-44, 2003.

[19] P. C. B. Phillips and H. R. Moon, "Linear regression limit theory for nonstationary panel data," Econometrica, vol. 67, no. 5, pp. 1057-1111, 1999.

[20] K. S. Im, M. H. Pesaran, and Y. Shin, "Testing for unit roots in heterogeneous panels," Journal of Econometrics, vol. 115, no. 1, pp. 53-74, 2003.

[21] P. Pedroni, "Fully modified OLS for heterogeneous cointegrated panels," Advances in Econometrics, vol. 15, pp. 93-130, 2000.

[22] C. Kao and M. H. Chiang, "On the estimation and inference of a cointegrated regression in panel data," Advances in Econometrics, vol. 15, pp. 179-222, 2000.

[23] F. J. Chaloupka and K. E. Warner, "The economics of smoking," in Handbook of Health Economics, A. J. Culyer and J. P. Newhouse, Eds., vol. 1, pp. 1549-1627, Elsevier Science, 2000.

[24] Centers for Disease Control and Prevention, "Response to increases in cigarette prices by race/ethnicity, income, and age groups-United States, 1976-1993," Morbidity and Mortality Weekly Report, vol. 47, pp. 605-609, 1998.

[25] R. L. Ohsfeldt, R. G. Boyle, and E. Capilouto, "Effects of tobacco excise taxes on the use of smokeless tobacco products in the USA," Health Education, vol. 6, pp. 525-531, 1997.

[26] F. J. Chaloupka, "Rational addictive behavior and cigarette smoking," Journal of Political Economy, vol. 99, no. 4, pp. 722$742,1991$.

[27] J. Gruber, Youth smoking in the US prices and policies, 2000, http://papers.nber.org/papers/W5706.

[28] E. M. Lewit, D. Coate, M. Grossman, and L. Benham, "The effects of government regulation on teenage smoking," Journal of Law and Economics, vol. 24, no. 3, pp. 545-573, 1981.

[29] E. M. Lewit, A. Hyland, N. Kerrebrock, and K. M. Cummings, "Price, public policy, and smoking in young people," Tobacco Control, vol. 6, supplement 2, pp. S17-24, 1997.

[30] J. Wasserman, W. G. Manning, J. P. Newhouse, and J. D. Winkler, "The effects of excise taxes and regulations on cigarette smoking," Journal of Health Economics, vol. 10, no. 1, pp. 43-64, 1991.

[31] D. P. Hopkins, P. A. Briss, C. J. Ricard et al., "Reviews of evidence regarding interventions to reduce tobacco use and exposure to environmental tobacco smoke," American Journal of Preventive Medicine, vol. 20, no. 2, pp. 16-66, 2001.

[32] T. E. Keeler, T. W. Hu, P. G. Barnett, W. G. Manning, and H. Y. Sung, "Do cigarette producers price-discriminate by state? An empirical analysis of local cigarette pricing and taxation," Journal of Health Economics, vol. 15, no. 4, pp. 499-512, 1996.

[33] Centers for Disease Control and Prevention, Community Guide Branch, National Center for Health Marketing NCHM: Decreasing tobacco use in worksite settings: smoke-free policies to reduce tobacco use among workers, 2009, http:// www.thecommunityguide.org/tobacco/worksite/smokefreepolicies.html.

[34] S. Zaza and J. D. Pickett, "The Guide to Community Preventive Services: update on development and dissemination activities," Journal of Public Health Management and Practice, vol. 7, no. 1, pp. 92-94, 2001. 
[35] M. Siegel, A. B. Albers, D. M. Cheng, L. Biener, and N. A. Rigotti, "Effect of local restaurant smoking regulations on progression to established smoking among youths," Tobacco Control, vol. 14, no. 5, pp. 300-306, 2005.

[36] E. A. Gilpin, M. M. White, A. J. Farkas, and J. P. Pierce, "Home smoking restrictions: which smokers have them and how they are associated with smoking behavior," Nicotine and Tobacco Research, vol. 1, no. 2, pp. 153-162, 1999.

[37] M. Skeer, D. M. Cheng, N. A. Rigotti, and M. Siegel, "Secondhand smoke exposure in the workplace," American Journal of Preventive Medicine, vol. 28, no. 4, pp. 331-337, 2005.

[38] IARC, Handbook of Cancer Prevention, Tobacco Control, vol. 12, Methods for Evaluating Tobacco Control Policies, 2008.

[39] H. Völzke, H. Neuhauser, S. Moebus et al., "Urban-rural disparities in smoking behaviour in Germany," BMC Public Health, vol. 6, article 146, 2006.

[40] H. Pesaran, "A Simple Panel Unit Root Test in the Presence of Cross Section Dependence," Cambridge working papers in economics 0346, faculty of economics (DAE), University of Cambridge, 2003. 


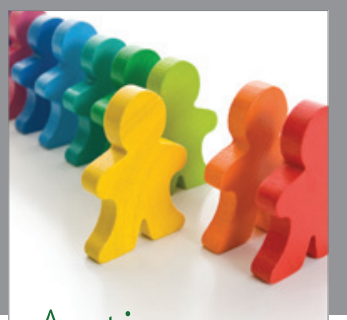

Autism

Research and Treatment
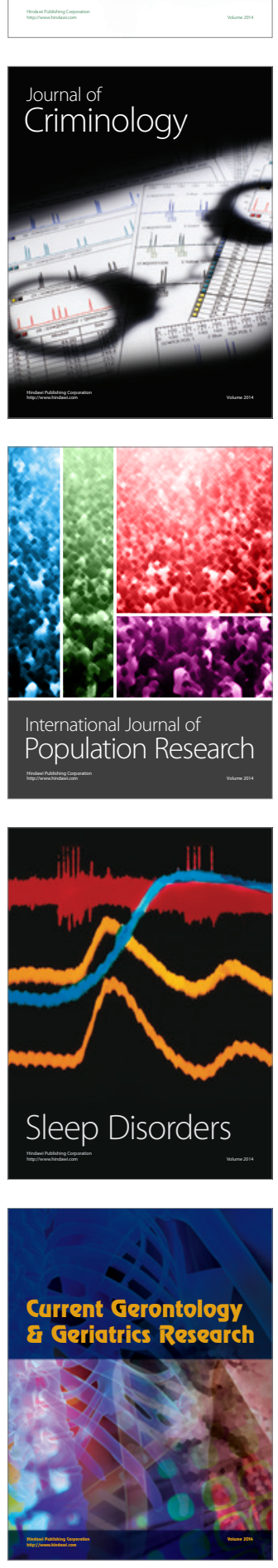
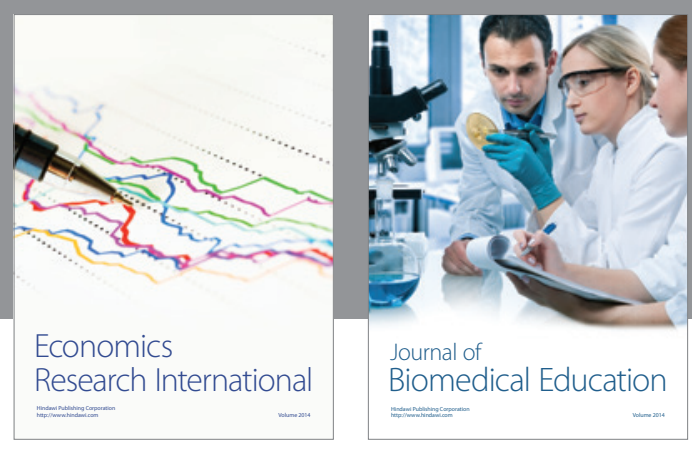

Journal of

Biomedical Education

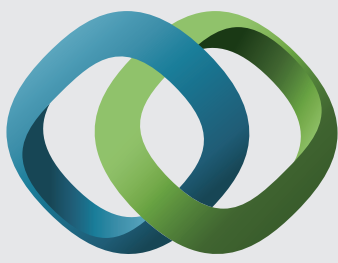

\section{Hindawi}

Submit your manuscripts at

http://www.hindawi.com
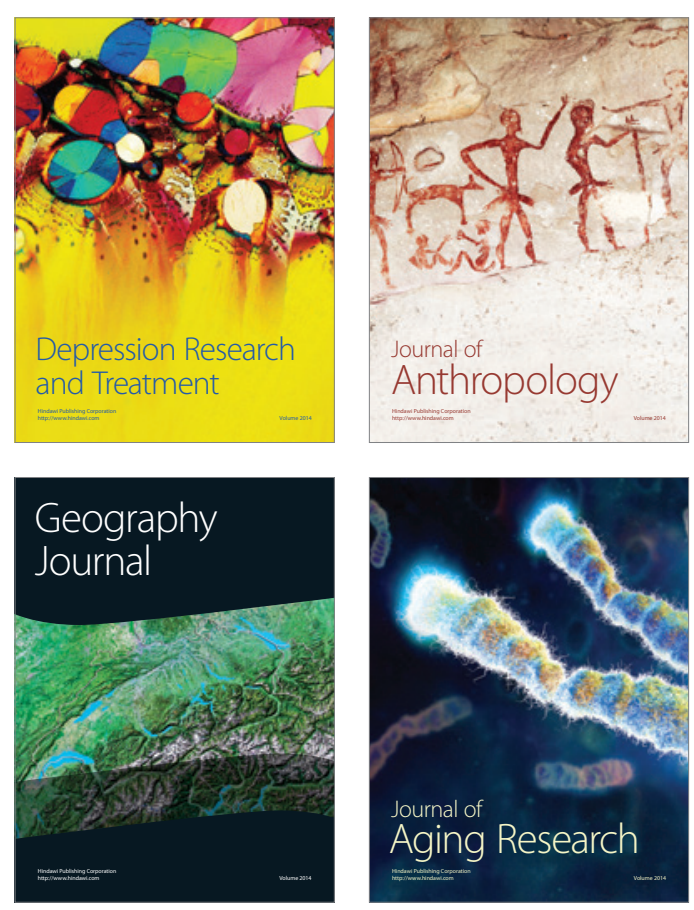

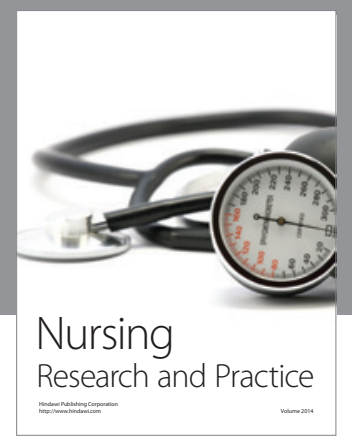

Nursing

Research and Practice

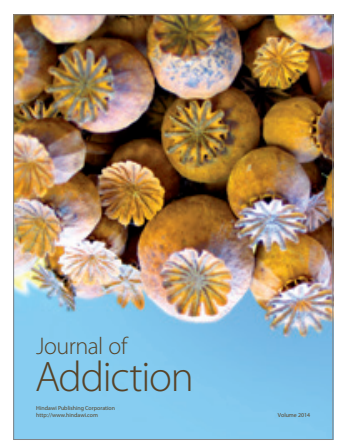

Child Development

Research

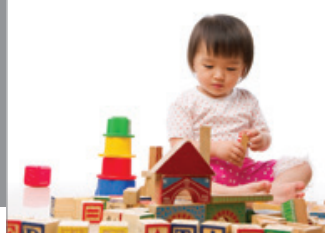

迥
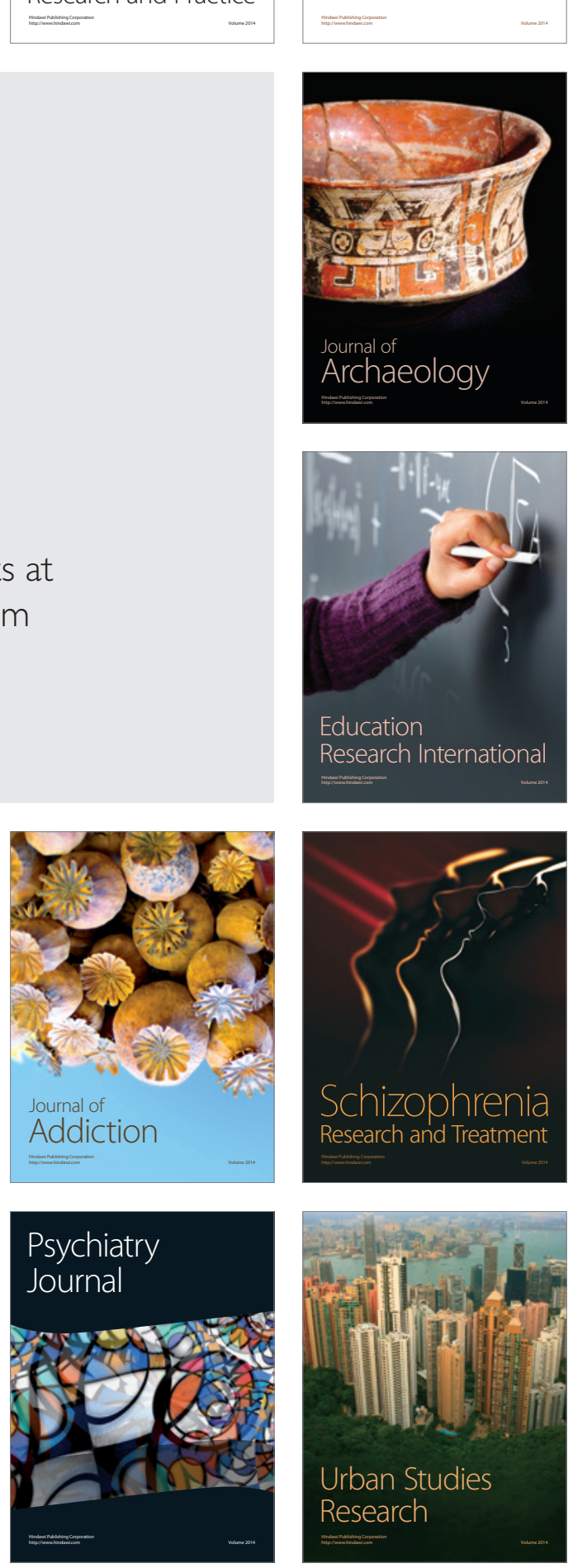